\title{
Genetic polymorphisms of angiotensin-2 type I receptor and angiotensinogen and risk of renal dysfunction and coronary heart disease in type 2 diabetes mellitus
}

\author{
Julie Lin*1,2, Frank B Hu ${ }^{1,3,4}$, Lu Qi1,3 and Gary C Curhan1,2,4
}

Address: ${ }^{1}$ Channing Laboratory, Department of Medicine, Brigham and Women's Hospital, Harvard Medical School, Boston, MA, USA, 2 Renal Division, Department of Medicine, Brigham and Women's Hospital, Harvard Medical School, Boston, MA, USA, ${ }^{3}$ Department of Nutrition, Harvard School of Public Health, Boston, MA, USA and ${ }^{4}$ Department of Epidemiology, Harvard School of Public Health, Boston, MA, USA

Email: Julie Lin* - jlin11@partners.org; Frank B Hu - nhbfh@channing.harvard.edu; Lu Qi - nhlqi@channing.harvard.edu;

Gary C Curhan - gcurhan@partners.org

* Corresponding author

Published: 27 March 2009

BMC Nephrology 2009, 10:9 doi:10.1 186/1471-2369-10-9
Received: 9 December 2008

Accepted: 27 March 2009

This article is available from: http://www.biomedcentral.com/I47I-2369/10/9

(C) 2009 Lin et al; licensee BioMed Central Ltd.

This is an Open Access article distributed under the terms of the Creative Commons Attribution License (http://creativecommons.org/licenses/by/2.0), which permits unrestricted use, distribution, and reproduction in any medium, provided the original work is properly cited.

\begin{abstract}
Background: Increased activation of the renin-angiotensin system (RAS) may be important in promoting coronary heart disease (CHD) and renal dysfunction, but limited data are available on associations between angiotensin type I receptor $(A G T I R)$ and angiotensinogen $(A G T)$ genotypes in type 2 diabetes.

Methods: Study participants were diabetics from the Health Professionals Follow-Up Study (HPFS) and the Nurses' Health Study (NHS). We analyzed single nucleotide polymorphisms (SNPs) associated with cardiovascular pathophysiology (including AGTIR T573C, AGTIR AII66C, and AGT M235T) and presence of renal dysfunction (eGFR $<60 \mathrm{ml} / \mathrm{min} / \mathrm{l} .73 \mathrm{~m}^{2}$ ) or history of CHD.

Results: The AGTIR I I 66 C-allele was associated with eGFR $<60 \mathrm{ml} / \mathrm{min} / 1.73 \mathrm{~m}^{2}$ (multivariable OR $1.63[1.01,2.65])$ in the HPFS men $(n=733)$ and in the combined dataset $(n=1566)($ OR I.42 [I.02, I.98]). The AGTIR II 66 C-allele was also associated with CHD in men (OR I.57 [I.I0, 2.24]). In NHS women ( $\mathrm{n}=833)$, AGT 235T-allele was associated with CHD (OR 1.72 [1.20, 2.47]). Removal of hypertension from the fully adjusted models did not influence results, suggesting that the associations may not be mediated by hypertension. There were significant interactions between sex and AGTIR II66 C-allele $(\mathrm{p}=0.008)$ and AGT M235T $(\mathrm{p}=0.03)$ in models for CHD. No significant associations were seen between AGTIR T573 C-allele and renal dysfunction or CHD.

Conclusion: Polymorphisms in AGTIR and AGT genes are associated with renal dysfunction and CHD in type 2 diabetes and further support the important role of the RAS in these complications. Sex may modify associations between AGTIR II66 C-allele and AGT 235T and CHD in type 2 diabetes.
\end{abstract}

\section{Background}

Increased activation of the renin-angiotensin system (RAS) has been postulated to play a central role in the progression of chronic kidney disease (CKD) and coronary heart disease (CHD). This theory is supported by randomized clinical trials that have shown beneficial clinical effects of the blockade of production of angiotensin-II (AII) by angiotensin converting enzyme inhibitor (ACE-I) 
medications or antagonism of AII action through angiotensin receptor blockade (ARBs). For example, among diabetics, the ARB losartan significantly slowed progression of CKD [1], whereas the ACE-I medication ramipril significantly reduced CHD morbidity and mortality [2].

Although the D-allele of the ACE I/D polymorphism has been associated with diabetic nephropathy in two large meta-analyses of several thousand individuals $[3,4]$, the role of genetic polymorphisms in other components of the RAS in CKD and CHD in people with type 2 diabetes has been less well defined. Associations between these SNPs and renal and cardiovascular diseases have been reported in other sub-groups, however. For example, the homozygous AGT (angiotensinogen gene) 235-T/T genotype has been associated with faster progression to ESRD in patients with glomerulonephritis [5] and with susceptibility to nephropathy in patients with type I diabetes mellitus [6], although not in two populations with type 2 diabetes $[7,8]$.

Higher concentrations of plasma angiotensinogen are associated with the AGT 235 T-allele [9] and may be directly related to the number of Thr alleles present [10] thereby supporting the theory that components in the RAS are physiologically activiated and may promote glomerulosclerosis and interstitial fibrosis via accumulation of extracellular matrix [11]. Recent research has revealed that another more clinically relevant AGT polymorphism may be a linked promoter substitution that increases the rate of gene transcription; this G-6A polymorphism appears to be the one most strongly associated with hypertension [12]. Genetic variation in AGT genes, especially the AGT 235T and AGT (-6) G alleles have also been reported to be associated with CHD $[10,13,14]$.

Angiotensin II type 1 receptor (AT1R) polymorphisms may influence intrarenal angiotensin II (AngII) activity. Healthy Caucasians carrying the A1166 C-allele (AC or CC) polymorphism showed lower basal GFR and basal renal plasma flow and had increases in GFR following treatment with the AT1R blocker losartan [15].

We therefore investigated associations of genetic polymorphisms in the AGT1R and AGT genes including AGT1R T573C, AGT1R A1166C, and AGT M235T and presence of CKD and CHD in type 2 diabetes.

\section{Methods}

\section{Participants}

Health Professionals' Follow-Up Study

The Health Professionals' Follow-Up Study (HPFS) was established in 1986 when 51,529 U.S. male health professionals, aged 40 to 75 at study initiation, returned a mailed questionnaire providing information about diet, lifestyle factors, and medical history [16]. Participants were mailed follow-up questionnaires every two years to update information. In 1993-1994, 18,159 participants provided blood samples that were shipped on ice by overnight delivery and stored at -130 degrees Celsius as previously described [17]. Diabetes mellitus (DM) was first identified by self-report on a biennial questionnaire and confirmed by a Diabetes Supplemental Questionnaire (DSQ) in 2000; the validity of the DSQ in confirming DM has been demonstrated in the HPFS cohort [18]. The HPFS DM blood cohort consists of 1000 men with confirmed diabetes at baseline who provided a blood sample in 1993-1994. Exclusion criteria for the current analyses were as follows: a) age of onset of DM $\leq 25$ years of age (to attempt to restrict the study to type $2 \mathrm{DM})(\mathrm{n}=31)$, b) subjects with a reported date of DM diagnosis after the date of blood draw $(\mathrm{n}=224), \mathrm{c})$ participants who reported on the DSQ that they were on dialysis $(n=9)$ or had a kidney transplant $(\mathrm{n}=1), \mathrm{d})$ serum creatinine $>5.0$ $\mathrm{mg} / \mathrm{dl}(\mathrm{n}=1)$, and e) serum creatinine $\leq 0.5 \mathrm{mg} / \mathrm{dl}$ (felt to be physiologically implausible) $(\mathrm{n}=1)$. After these exclusions, 733 men were available for analysis.

\section{Nurses' Health Study}

The NHS was initiated in 1976 with the enrollment of 121,700 U.S. nurses aged $30-55$ years. This cohort is followed through questionnaires related to lifestyle factors and health outcomes that are mailed biennially. In 1989, 32,826 participants provided blood samples that were shipped on ice by overnight delivery and stored at -130 degrees Celsius as previously described [19]. Of these study participants who provided blood samples in 1989$1990,1,198$ who had a confirmed diagnosis of type 2 diabetes were chosen as a NHS diabetes blood sub-cohort. Exclusion criteria for the current analyses were: a) age of onset of DM $\leq 25$ years of age (to attempt to restrict the study to type $2 \mathrm{DM})(\mathrm{n}=39)$, b) subjects with a reported date of DM diagnosis after the date of blood draw ( $\mathrm{n}=$ 304 ), and c) serum creatinine $\leq 0.5 \mathrm{mg} / \mathrm{dl}$ (likely to be a laboratory error and physiologically implausible) $(\mathrm{n}=$ 22). No NHS participants reported on the DSQ being on dialysis or having had a kidney transplant. After these exclusions, 833 women had data available for analysis.

This study was approved by the Partners' Healthcare Brigham and Women's Hospital Human Research Committee Institutional Review Board.

\section{Assessment of covariates}

Race was initially reported on the 1986 questionnaire for HPFS and in 1992 for NHS. Other clinical and lifestyle variables were derived from data from the questionnaire closest to the blood collection, i.e. the 1994 questionnaire for HPFS and the 1990 questionnaire for NHS. Body mass index (BMI) was calculated by weight $\left(\mathrm{kg} / \mathrm{m}^{2}\right)$. A weekly 
metabolic-equivalent (MET) score was calculated from the physical activity questions. Self-reported hypertension [18] and smoking status [20] have also been previously validated in these cohorts.

\section{Laboratory Methods}

Single-nucleotide polymorphisms (SNP) analyses

DNA was extracted from the buffy coat fraction of centrifuged blood using the QIAmp Blood Kit (Qiagen, Chatsworth, CA). All SNPs were genotyped using Taqman SNP allelic discrimination by means of an ABI 7900 HT (Applied Biosystems, Foster City, CA). Undetermined SNP results, which comprised of $<10 \%$ of data for any individual SNP, were treated as missing values. The candidate SNPs investigated here were AGT1R T573C (rs5182), AGT1R A1166C (rs5186), AGT M235T (rs699), and AGT $A(-6) G(r 55051)$. A concordance rate of $100 \%$ was seen in 108 blinded quality control samples for all SNPs assayed.

\section{Estimation of kidney function}

Plasma creatinine was measured by a modified kinetic Jaffe reaction with a coefficient of variation of $22 \%$ for HPFS and $10 \%$ for NHS. Renal function was estimated by the simplified MDRD equation where estimated glomerular filtration rate $($ eGFR $)\left(\mathrm{ml} / \mathrm{min} / 1.73 \mathrm{~m}^{2}\right)=186 \times[\mathrm{PCr}$ $(\mathrm{mg} / \mathrm{dl})]^{-1.154} \times[\text { Age }]^{-0.203} \times[0.472$ if female $] \times[1.21$ if black] [21] and the Cockcroft-Gault equation where estimated creatinine clearance $(\mathrm{CrCl})=([140$-age $($ years $) \times$ weight $(\mathrm{kg}) \times(0.8$ if female $)] /(\mathrm{Pcr} \times 72))[22]$. Moderate renal dysfunction was considered to be eGFR $<60 \mathrm{ml} /$ $\mathrm{min} / 1.73 \mathrm{~m}^{2}$ or $\mathrm{CrCl}<60 \mathrm{ml} / \mathrm{min}$. Because results using $\mathrm{CrCl}<60 \mathrm{ml} / \mathrm{min}$ were very similar to those using eGFR $<$ $60 \mathrm{ml} / \mathrm{min} / 1.73 \mathrm{~m}^{2}$, we present only the eGFR analyses.

\section{Ascertainment of Coronary Heart Disease}

Coronary heart disease was defined as history of confirmed myocardial infarction, or self-reported coronary revascularization or angina. These self-reported outcomes have been previously validated by medical chart review [23].

\section{Statistical Analyses}

In our primary analyses, we tested for associations of SNPs and outcomes using a dominant model where the presence of the disease allele (listed second in the SNP name as per convention) was considered the exposure of interest. We also examined recessive models, where the homozygous disease genotype was compared to all others, as well as additive genetic models, where the impact of each additional presumed disease allele was assessed.

Unconditional logistic regression was used to calculate odds ratios for GFR $<60 \mathrm{ml} / \mathrm{min} / 1.73 \mathrm{~m}^{2}$ or $\mathrm{CrCl}<60 \mathrm{ml} /$ min or presence of CHD. Multivariable models were adjusted for age (continuous, years), hypertension (yes/ no), BMI (continuous), cigarette smoking status (never, past, current), physical activity (quartiles, METS/week), duration of type 2 diabetes (quartiles, years), and measured HgbA1c (quartiles). In the analyses of the combined cohorts, sex was included as a covariate in addition to all those variables included in fully-adjusted models stratified by sex. Coronary heart disease (yes/no) was also included as a covariate in models where eGFR $<60 \mathrm{ml} /$ $\mathrm{min} / 1.73 \mathrm{~m}^{2}$ or $\mathrm{CrCl}<60 \mathrm{ml} / \mathrm{min}$ were the outcome of interest. Estimated GFR $<60 \mathrm{ml} / \mathrm{min} / 1.73 \mathrm{~m}^{2}$ was included as a covariate for CHD analyses. All analyses were performed with SAS software, version 9.1 (SAS Institute, Inc., Cary, North Carolina).

\section{Results}

Demographic and clinical information for HPFS and NHS participants with Type 2 diabetes are shown in Table 1. Participants were predominantly Caucasian, the majority was overweight or obese, and the mean time since diagnosis of type 2 diabetes was 10 to 11 years. Most participants had well-preserved renal function: only 90 HPFS men and 80 NHS women had eGFR $<60 \mathrm{ml} / \mathrm{min} / 1.73 \mathrm{~m}^{2}$. Approximately $25 \%$ of participants had prevalent CHD. Only 38 (5\%) participants in HPFS and $42(5 \%)$ participants in NHS had both eGFR $<60 \mathrm{ml} / \mathrm{min} / 1.73 \mathrm{~m}^{2}$ and CHD.

AGT A(-6)G is in complete linkage disequilibrium with M235T and results were almost identical between the two SNPs; therefore, we present only the results for AGT SNPs from the M235T analyses. Prevalence of the disease-associated allele ranged from $47 \%$ for AGT1R 1166 C-allele to $68 \%$ for the AGT1R 573 C-allele. Prevalence of homozygosity for the disease-associated allele ranged from $9 \%$ for AGT1R 1166 C-allele to $20 \%$ for the AGT1R 573 C-allele. The SNPs were in Hardy-Weinberg equilibrium (all p-values for chi-square test $\geq 0.60$ ).

For all SNPs, the magnitude of the fully adjusted odds ratios for the dominant models showed little difference when compared to the age-adjusted only models (Table 2 ). For the outcome of eGFR $<60 \mathrm{ml} / \mathrm{min} / 1.73 \mathrm{~m}^{2}$, a significantly elevated odds ratio was seen in the fullyadjusted model for the AGT1R $1166 \mathrm{C}$-allele in the HPFS men only (Table 2). Adjusted dominant models that did not include prevalent hypertension for the outcome of eGFR $<60 \mathrm{ml} / \mathrm{min} / 1.73 \mathrm{~m}^{2}$ were not different from the fully adjusted models. When the two cohorts were combined, the AGT1R 1166 C-allele remained significantly associated with eGFR $<60 \mathrm{ml} / \mathrm{min} / 1.73 \mathrm{~m}^{2}$ (adjusted OR $1.42[1.02,1.98]$ ) (Figure 1); no significant associations were seen in recessive or additive models in the combined dataset. Results using $\mathrm{CrCl}<60 \mathrm{ml} / \mathrm{min}$ as the outcome of interest were similar to those using eGFR $<60 \mathrm{ml} / \mathrm{min} /$ $1.73 \mathrm{~m}^{2}$ (results not shown). 
Table I: Demographic and clinical characteristics of type 2 diabetics in the Health Professionals Follow-Up Study (HPFS) and Nurses' Health Study (NHS)

\begin{tabular}{|c|c|c|}
\hline & $\begin{array}{c}\text { HPFS in } 1994 \\
(n=733)\end{array}$ & $\begin{array}{c}\text { NHS in } 1990 \\
(n=833)\end{array}$ \\
\hline Age (years) & $65.5 \pm 7.9(47-80)$ & $59.5 \pm 6.3(43-70)$ \\
\hline African-American & II (I.5) & $12(1.4)$ \\
\hline Hypertension & $399(45.6)$ & $568(68.2)$ \\
\hline Weight (kg) & $88.1 \pm 16.2(56.8-210.9)$ & $80.4 \pm 18.1(38.6-154.5)$ \\
\hline Body Mass Index (BMI) $\left(\mathrm{kg} / \mathrm{m}^{2}\right)$ & $27.8 \pm 4.4(18.3-56.5)$ & $29.9 \pm 6.2(15.1-54.9)$ \\
\hline \multicolumn{3}{|l|}{ BMI categories $\left(\mathrm{kg} / \mathrm{m}^{2}\right)$} \\
\hline$<22$ & $33(4.5)$ & $78(9.3)$ \\
\hline $22-24.9$ & $160(21.8)$ & $102(12.2)$ \\
\hline $25-27.9$ & $229(3 \mid .2)$ & $155(18.6)$ \\
\hline $28-29.9$ & $131(17.9)$ & $110(13.2)$ \\
\hline$\geq \mathbf{3 0}$ & $180(24.6)$ & $384(46.1)$ \\
\hline Activity (METs/week) & $29.6 \pm 33.0(0-228.8)$ & $15.3 \pm 20.3(0.2-190.7)$ \\
\hline \multicolumn{3}{|l|}{ Cigarette smoking } \\
\hline Current & $43(5.8)$ & $113(13.6)$ \\
\hline Past & $392(53.5)$ & $341(40.9)$ \\
\hline Never & $261(35.7)$ & $377(45.3)$ \\
\hline Missing & $37(5.1)$ & $2(0.2)$ \\
\hline Time since diagnosis of Type 2 diabetes (years) & $11.2 \pm 9.1(0.1-41.1)$ & $10.3 \pm 8.0(0.1-41.1)$ \\
\hline Measured HbAlc (\%) & $7.5 \pm 1.6(4.8-15.6)$ & $7.2 \pm 1.8(4.4-15.4)$ \\
\hline Baseline coronary heart disease (MI, revascularization, or angina) & $194(26.5)$ & $216(25.9)$ \\
\hline ACE-inhibitor medication use & $60(8.2)$ & $81(9.7)$ \\
\hline Statin medication use & $48(6.6)$ & Not available \\
\hline Measured plasma creatinine $(\mathrm{mg} / \mathrm{dl})$ & $\mathrm{I} . \mathrm{I} \pm 0.2(0.6-2.9)$ & $0.8 \pm 0.2(0.5-2.4)$ \\
\hline Creatinine clearance $(\mathrm{ml} / \mathrm{min})$ & $91 \pm 30(22-241)$ & $100 \pm 33(17-244)$ \\
\hline eGFR $\left(\mathrm{ml} / \mathrm{min} / \mathrm{l} .73 \mathrm{~m}^{2}\right)$ & $79 \pm 18(23-142)$ & $83 \pm 19(22-139)$ \\
\hline
\end{tabular}

Results expressed as mean \pm SD (range 0 to $100 \%$ ) or no. (\%)

$\mathrm{ACE}=$ Angiotensin-converting enzyme

eGFR= Estimated glomerular filtration rate

For the outcome of CHD, the AGT1R $1166 \mathrm{C}$-allele in dominant model was associated with a significantly higher odds ratio in men while the AGT SNP M235T was associated with a significantly higher odds ratio in women (Table 2). Recessive inheritance modeling was borderline significant only for the AGT M235T (adjusted OR 1.52 [0.98 to 2.35]) for the presence of CHD in women. No recessive models were significant for men, and all additive models were null for both groups. Multivariable models that did not include prevalent hypertension yielded the same results as the fully adjusted models. Excluding eGFR $<60 \mathrm{ml} / \mathrm{min} / 1.73 \mathrm{~m}^{2}$ as a covariate in the models for CHD also did not influence the associations seen.

The AGT 235 T-allele had a borderline association with history of CHD (OR 1.24 [0.96, 1.61] in the pooled data (Figure 1). The fully adjusted odds ratios for the combined data were not notably different from the ageadjusted only odds ratios (all differences resulted in <
$10 \%$ change in OR). Results for CHD outcome did vary by sex; we observed significant interaction term p-values for the AGT1R $1166 \mathrm{C}$-allele ( $\mathrm{p}=0.008)$ and AGT 235 T-allele $(\mathrm{p}=0.03)$ in relation to CHD (Table 2$)$. In the combined data set, no significant associations were observed in recessive or additive models for $\mathrm{CHD}$.

Because different allelic frequencies may be seen in different ethnic populations, we also analyzed these data with the few African-Americans excluded. Exclusion of these participants did not meaningfully change any of the results in the analyses stratified by sex or in the combined cohort. For example, the odds ratio for AGT1R A1166 Callele was $1.70[1.04,2.78]$ for $e G F R<60 \mathrm{ml} / \mathrm{min} / 1.73 \mathrm{~m}^{2}$ and $1.56[1.09,2.21]$ for CHD when African-Americans were excluded from the HPFS analyses. Similarly in the combined cohort, the odds ratio for AGT1R A1166 Callele and $\mathrm{eGFR}<60 \mathrm{ml} / \mathrm{min} / 1.73 \mathrm{~m}^{2}$ was $1.42[1.02$ to 1.98]. 


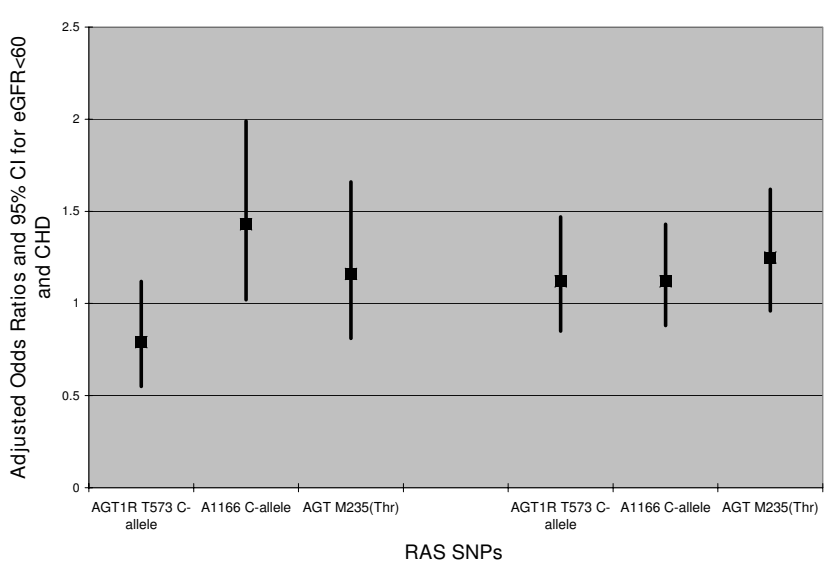

Figure I

Adjusted odds ratios for dominant model RAS SNPs and eGFR $<60 \mathrm{ml} / \mathrm{min} / 1.73 \mathrm{~m}^{2}$ and CHD in combined cohort of HPFS (men) and NHS (women) with type 2 diabetes. Error bars represent $95 \%$ confidence intervals.

\section{Discussion}

The AGT1R 1166 C-allele was directly and significantly associated with renal dysfunction in the combined dataset. This SNP was also associated with higher odds ratio for prevalent CHD in men with type 2 diabetes whereas the AGT 235 T-allele was significantly associated with increased odds ratio for CHD in women with type 2 diabetes. In contrast to the majority of previous publications of AGT1R and AGT polymorphisms, this study only included adults with type 2 diabetes, which is a population especially at high risk for kidney dysfunction and CHD.

We also found that sex might modify the association between SNPs and presence of CHD, and recommend that future investigations consider stratifying analyses by sex. A biological basis for these observed sex differences may be indirectly supported by previous studies of the RAS. For example, a population study of several hundred Bavarians revealed higher renin and prorenin levels in men compared with women; the authors also noted the lowest renin and prorenin levels in women taking hormone replacement therapy and hypothesized that sex hormones may regulate expression of the renin gene [24]. Healthy men also exhibit greater decreases in plasma renin and angiotensin-II levels than healthy women when given angiotensin-receptor blocker medications [25]. Another investigation of 93 healthy young men and women also reported higher levels of angiotensin-(1-7) peptides in men compared to women, but did not detect significant differences in levels of A-I, A-II, or angiotensin(1-7) between the sexes when stratified by AGT1R 1166 C-allele or AGT M235T genotypes [26]; however, the study had low power because many subgroups analyzed had less than 10 people.

We examined dominant, recessive, and additive genetic models for each of these four SNPs and eGFR $<60 \mathrm{ml} /$ $\mathrm{min} / 1.73 \mathrm{~m}^{2}$ and CHD and did not detect significant associations with recessive models or additive models. Previous analyses of the AGT M235T SNP and CHD have reported an association with the homozygous $\mathrm{T} / \mathrm{T}$ variant $[10,13,14]$, but these relatively small studies may not have had enough power to effectively identify recessive genetic effects.

Our findings that the AGT1R 1166 C-allele was associated with renal dysfunction in men and women with type 2 diabetes is consistent with a smaller French study of 235 type 2 diabetics where the authors reported that the CC genotype was significantly associated with nephropathy (defined as presence of microalbuminuria) especially in men[27]. Although previous case-control studies demonstrated an increased frequency of the AGT1R $1166 \mathrm{C}$-allele in ESRD patients with [28] and without type 2 diabetes [29] compared to healthy controls, our study appears to be one of the few to examine an earlier stage of moderate kidney dysfunction. In contrast, other studies have not found association between A1166 C-allele and nephropathy in type 2 diabetes [30,31].

Consistent with our findings, however, a study of 132 Japanese adults with type 2 diabetes [32], a Hong Kong study of 168 type 2 diabetics [33], a study from Germany of 301 type 2 diabetics [34], and a meta-analysis of several thousand people [35] reported no association between nephropathy and the AGT M235T polymorphism. In contrast, a recent investigation of 421 Asian Indian type 2 diabetics did find an association between the AGT 235 T-allele and renal insufficiency (defined as plasma creatinine $\geq 3 \mathrm{mg} /$ $\mathrm{dl}$ and/or urinary albumin excretion rate $>200 \mathrm{mcg} / \mathrm{min}$ ) (OR 2.68, 95\%CI 2.01 to 3.57) [36].

Direct comparisons of conflicting reports in the literature, however, may be difficult and discrepancies could be due to many factors such different prevalence in genetic polymorphisms in different ethnic populations as well as varying definitions of nephropathy (impaired eGFR or $\mathrm{CrCl}$ in our study vs. microalbuminuria in other studies) and varying sample sizes. For example, the frequencies of the AGT 235 T-allele and the AGT (-6) G-allele appear to be much higher in Japanese compared with Caucasian populations [12].

Interestingly, the associations observed between these candidate RAS SNPs and renal dysfunction were not meaningfully changed after multivariable adjustment. In particular, excluding hypertension as a covariate from the 
Table 2: Logistic regression dominant models for association of RAS SNPs with presence of moderate renal dysfunction (GFR $<60$ ml/ $\mathrm{min} / 1.73 \mathrm{~m}^{2}$ ) or CHD

\begin{tabular}{|c|c|c|c|c|c|c|c|}
\hline & & HPFS $(n=733)$ & & & NHS $(n=833)$ & & \\
\hline & $\begin{array}{c}\text { Number of } \\
\text { cases/Total } \\
\text { number with } \\
\text { allele (\%) }\end{array}$ & $\begin{array}{c}\text { Age-adjusted } \\
\text { OR } \\
{[95 \% \mathrm{Cl}]}\end{array}$ & $\begin{array}{c}\text { Multivariable } \\
\text { OR* } \\
{[95 \% \mathrm{CI}]}\end{array}$ & $\begin{array}{c}\text { Number of } \\
\text { cases/Total } \\
\text { number with } \\
\text { allele (\%) }\end{array}$ & $\begin{array}{c}\text { Age-adjusted } \\
\text { OR } \\
{[95 \% \mathrm{CI}]}\end{array}$ & $\begin{array}{c}\text { Multivariable } \\
\text { OR* } \\
{[95 \% \mathrm{Cl}]}\end{array}$ & $\begin{array}{l}\text { p-value for } \\
\text { sex *SNP } \\
\text { interaction }\end{array}$ \\
\hline \multicolumn{8}{|l|}{$\begin{array}{l}\text { For GFR }<60 \\
\mathrm{ml} / \mathrm{min} / 1.73 \mathrm{~m}^{2}\end{array}$} \\
\hline $\begin{array}{l}\text { AGTIR } \\
\text { T573C } \\
\text { (C-allele) }\end{array}$ & $\begin{array}{c}54 / 480 \\
(11 \%)\end{array}$ & $\begin{array}{c}0.68 \\
{[0.42,1.09]}\end{array}$ & $\begin{array}{c}0.60 \\
{[0.36,1.00]}\end{array}$ & $68 / 569$ (12\%) & $\begin{array}{c}1.11 \\
{[0.68,1.82]}\end{array}$ & $\begin{array}{c}0.96 \\
{[0.57,1.61]}\end{array}$ & 0.21 \\
\hline $\begin{array}{l}\text { AGTIR } \\
\text { AII66C } \\
\text { (C-allele) }\end{array}$ & $\begin{array}{l}51 / 346 \\
(15 \%)\end{array}$ & $\begin{array}{c}1.59 \\
{[0.99,2.49]}\end{array}$ & $\begin{array}{c}1.63 \\
{[1.01,2.65]}\end{array}$ & $50 / 402(12 \%)$ & $\begin{array}{c}1.18 \\
{[0.76,1.83]}\end{array}$ & $\begin{array}{c}1.28 \\
{[0.80,2.04]}\end{array}$ & 0.54 \\
\hline $\begin{array}{l}\text { AGT } \\
\text { M235T } \\
\text { (Thr) }\end{array}$ & $\begin{array}{c}57 / 469 \\
(12 \%)\end{array}$ & $\begin{array}{c}0.98 \\
{[0.61,1.56]}\end{array}$ & $\begin{array}{c}0.91 \\
{[0.55,1.49]}\end{array}$ & $68 / 527$ (13\%) & $\begin{array}{c}1.62 \\
{[0.99,2.69]}\end{array}$ & $\begin{array}{c}1.46 \\
{[0.85,2.50]}\end{array}$ & 0.25 \\
\hline \multicolumn{8}{|l|}{$\begin{array}{l}\text { For prevalent } \\
\text { CHD }\end{array}$} \\
\hline $\begin{array}{l}\text { AGTIR } \\
\text { T573C } \\
\text { (C-allele) }\end{array}$ & $133 / 480(28 \%)$ & $\begin{array}{c}1.26 \\
{[0.85,1.85]}\end{array}$ & $\begin{array}{c}1.36 \\
{[0.91,2.02]}\end{array}$ & $148 / 569(26 \%)$ & $\begin{array}{c}1.07 \\
{[0.75,1.53]}\end{array}$ & $\begin{array}{c}1.02 \\
{[0.69,1.49]}\end{array}$ & 0.45 \\
\hline $\begin{array}{l}\text { AGTIR } \\
\text { AlI66C } \\
\text { (C-allele) }\end{array}$ & $105 / 346(30 \%)$ & $\begin{array}{c}1.62 \\
{[1.14,2.29]}\end{array}$ & $\begin{array}{c}1.57 \\
{[1.10,2.24]}\end{array}$ & $99 / 402$ (25\%) & $\begin{array}{c}0.84 \\
{[0.61,1.16]}\end{array}$ & $\begin{array}{c}0.85 \\
{[0.61,1.20]}\end{array}$ & 0.008 \\
\hline $\begin{array}{l}\text { AGT } \\
\text { M235T } \\
\text { (Thr) }\end{array}$ & $120 / 469(26 \%)$ & $\begin{array}{c}0.95 \\
{[0.66,1.35]}\end{array}$ & $\begin{array}{c}0.92 \\
{[0.64,1.33]}\end{array}$ & I54/527 (29\%) & $\begin{array}{c}1.72 \\
{[1.20,2.47]}\end{array}$ & $\begin{array}{c}1.66 \\
{[1.13,2.43]}\end{array}$ & 0.03 \\
\hline
\end{tabular}

*Multivariable models are adjusted for age (continuous, years), hypertension (yes/no), BMI (continuous), cigarette smoking status (never, past, current), physical activity (quartiles, mets/week), time since Type 2 diabetes diagnosis (quartiles, years), and measured HbAlc (quartiles). Multivariable models for renal dysfunction are adjusted for presence of coronary heart disease (yes/no) and multivariable models for CHD are also adjusted for eGFR $<60 \mathrm{ml} / \mathrm{min} / \mathrm{I} .73 \mathrm{~m} 2$. ACE-inhibitor use did not change point estimates when included in the model and was removed. GFR $<60 \mathrm{ml} / \mathrm{min} / 1.73 \mathrm{~m}^{2}$ by the 4-variable MDRD equation was considered renal dysfunction. Coronary heart disease was defined as history of confirmed myocardial infarction, or self-reported coronary revascularization or angina.

model did not change results and support the concept that association between RAS SNPs (and presumed upregulation of the RAS) and renal and CHD outcomes may be mediated by other influences in besides hypertension, which likely include cellular hyperplasia, stimulation of hormonal pathways and direct pro-fibrotic effects on the kidneys and vasculature [11]. Other investigators have also reported that hypertension may not mediate associations between these SNPs and CHD [13] or progressive CKD [37]. Also notable is the lack of influence of including eGFR $<60 \mathrm{ml} / \mathrm{min} / 1.73 \mathrm{~m}^{2}$ as a covariate in models where CHD was the dependent variable, which may suggest that renal dysfunction has a weaker association with CHD in type 2 diabetes (who have often have multiple overlapping vascular risk factors) than in non-diabetic populations.

Some important limitations of this investigation need to be acknowledged. Data on albuminuria, another measure of kidney dysfunction in addition to eGFR or $\mathrm{CrCl}$ were not available in the men and the majority of the women.
Kidney function was not directly measured but estimated by a single measurement of plasma creatinine in each participant. The participants were mostly Caucasians and the findings may not be generalizable to other ethnic groups. There are no measurements of plasma angiotensiongen levels or other markers of RAS activation available to correlate directly with the genetic polymorphisms investigated here. The relatively small sample sizes and few numbers of participants meeting criteria for kidney dysfunction has resulted in wide confidence intervals for many of the estimates for eGFR $<60 \mathrm{ml} / \mathrm{min} / 1.73 \mathrm{~m}^{2}$. Also, as the DNA was collected several years after the initiation of the cohort study, there is a possibility that participants who died prior to the blood collection may have had the candidate SNPs; this situation would be expected to bias results towards the null, however, whereas we did observe a number of significant associations.

Strengths of the current study include the examination of genetic polymorphisms in the RAS that have received less attention than the ACE-I/D genotype, which provide 
novel information concerning genetics and kidney and cardiac disease in adults with type 2 diabetes. Furthermore, by examining the SNPs separately in a cohort of men and one of women as well as in a combined dataset, these analyses revealed that sex may modify the association between RAS gene polymorphisms and coronary heart disease in type 2 diabetes.

\section{Conclusion}

In conclusion, among type 2 diabetics, the AGT1R 1166 $\mathrm{C}$-allele is directly associated with kidney dysfunction in men and women but with CHD only in men. The AGT 235 T-allele is associated with CHD in women. Previous evidence suggests that these polymorphisms are associated with up-regulation of the RAS, and therefore, these data further support the central role of RAS activation in CKD and CHD.

\section{Competing interests}

The authors declare that they have no competing interests.

\section{Authors' contributions}

JL conceived of the study, obtained funding for the genotyping, performed statistical analyses, and drafted the manuscript. FBH established the HPFS and NHS diabetes subcohorts and obtained funding for DNA extraction. LQ participated in statistical analyses and edited the manuscript. GCC participated in the design of the study and edited the manuscript. All authors read and approved the final manuscript.

\section{Acknowledgements}

This work was supported by NIH grants K08 DK066246 (JL), ROIHL065582 (FBH), ROI DK066574 (GCC), POICA055075 and a Norman S. Coplon Extramural Research Grant through Satellite Healthcare (JL). A portion of this work was included in a poster presentation at Renal Week 2005, November 8 to 13, Philadelphia, PA.

\section{References}

I. Brenner BM, et al.: Effects of losartan on renal and cardiovascular outcomes in patients with type 2 diabetes and nephropathy. N Engl I Med 200I, 345( I 2):86I-9.

2. Effects of ramipril on cardiovascular and microvascular outcomes in people with diabetes mellitus: results of the HOPE study and MICRO-HOPE substudy. Heart Outcomes Prevention Evaluation Study Investigators. Lancet 2000, 355(9200):253-9.

3. Fujisawa T, et al.: Meta-analysis of association of insertion/deletion polymorphism of angiotensin I-converting enzyme gene with diabetic nephropathy and retinopathy. Diabetologia 1998 , $4 I(I): 47-53$.

4. Adamczak M, et al:: Ageing and plasma adiponectin concentration in apparently healthy males and females. Clin Endocrinol (Oxf) 2005, 62(1): I 14-8.

5. Lovati $E$, et al:: Genetic polymorphisms of the renin-angiotensin-aldosterone system in end-stage renal disease. Kidney International 200 I, 60(I):46-54.

6. Rogus JJ, et al.: Diabetic nephropathy is associated with AGT polymorphism T235: results of a family-based study. Hypertension 1998, 3 I(2):627-3I.

7. Schmidt AM, et al.: Elevated plasma levels of vascular cell adhesion molecule-I (VCAM-I) in diabetic patients with micro- albuminuria: a marker of vascular dysfunction and progressive vascular disease. BrJ Haematol 1996, 92(3):747-50.

8. Solini $A$, et al.: Polymorphisms of angiotensin-converting enzyme and angiotensinogen genes in type 2 diabetic sibships in relation to albumin excretion rate. American Journal of Kidney Diseases 1999, 34(6): 1002-9.

9. Sethi AA, et al:: Angiotensinogen single nucleotide polymorphisms, elevated blood pressure, and risk of cardiovascular disease. Hypertension 2003, 4 I (6): I 202-II.

10. Winkelmann BR, et al.: Angiotensinogen M235T polymorphism is associated with plasma angiotensinogen and cardiovascular disease. Am Heart J 1999, I 37(4 Pt I):698-705.

II. Matsusaka T, Ichikawa I: Biological functions of angiotensin and its receptors. Annual Review of Physiology 1997, 59:395-4I2.

12. Inoue I, et al.: A nucleotide substitution in the promoter of human angiotensinogen is associated with essential hypertension and affects basal transcription in vitro. Journal of Clinical Investigation 1997, 99(7): 1786-97.

13. Rodriguez-Perez JC, et al.: Association of angiotensinogen M235T and A(-6)G gene polymorphisms with coronary heart disease with independence of essential hypertension: the PROCAGENE study. Prospective Cardiac Gene. J Am Coll Cardiol 200I, 37(6): I536-42.

14. Buraczynska $M$, et al:: Renin-angiotensin system gene polymorphisms: assessment of the risk of coronary heart disease. Kardiol Pol 2003, 58(I): I-9.

15. Miller JA, Thai K, Scholey JW: Angiotensin II type I receptor gene polymorphism predicts response to losartan and angiotensin II[see comment]. Kidney International 1999, 56(6):2173-80.

16. Forman JP, et al.: Folate intake and the risk of incident hypertension among US women. Jama 2005, 293(3):320-9.

17. Schulze MB, et al.: Relationship between adiponectin and glycemic control, blood lipids, and inflammatory markers in men with type 2 diabetes. Diabetes Care 2004, 27(7):1680-7.

18. Abbott KC, et al.: Graft loss due to recurrent focal segmental glomerulosclerosis in renal transplant recipients in the United States. American Journal of Kidney Diseases 200I, 37(2):366-73.

19. Schulze $M B$, et al.: Dietary pattern, inflammation, and incidence of type 2 diabetes in women. Am J Clin Nutr 2005, 82(3):675-84.

20. Willett $W$, et al.: Cigarette smoking, relative weight, and menopause. Am J Epidemiol 1983, I I7(6):65I-8.

21. Recommendations for healthcare system and self-management education interventions to reduce morbidity and mortality from diabetes. Am J Prev Med 2002, 22(4 Suppl): 10-4.

22. Cockcroft DW, Gault MH: Prediction of creatinine clearance from serum creatinine. Nephron 1976, 16(1):31-41.

23. Tanasescu M, et al.: Physical activity in relation to cardiovascular disease and total mortality among men with type 2 diabetes. Circulation 2003, 107(19):2435-9.

24. Danser $\mathrm{AH}$, et al:: Determinants of interindividual variation of renin and prorenin concentrations: evidence for a sexual dimorphism of (pro)renin levels in humans. J Hypertens 1998, 16(6):853-62.

25. Miller JA, et al:: Gender differences in the renal response to renin-angiotensin system blockade. J Am Soc Nephrol 2006, I 7(9):2554-60.

26. Reyes-Engel A, et al.: Influence of gender and genetic variability on plasma angiotensin peptides. J Renin Angiotensin Aldosterone Syst 2006, 7(2):92-7.

27. Fradin S, et al:: Relationship between polymorphisms in the renin-angiotensin system and nephropathy in type 2 diabetic patients. Diabetes Metab 2002, 28(I):27-32.

28. Buraczynska $M$, et al:: [Association of the renin-angiotensin system gene polymorphism with nephropathy in type II diabetes]. Pol Arch Med Wewn 2002, 108(2):725-30.

29. Baker CS, et al.: A rapid protocol for the prevention of contrast-induced renal dysfunction: the RAPPID study. J Am Coll Cardiol 2003, 4 I ( I 2):2 I I 4-8.

30. Hunley TE, et al.: Angiotensin converting enzyme gene polymorphism: potential silencer motif and impact on progression in IgA nephropathy. Kidney International 1996, 49(2):571-7.

31. Gutierrez C, et al.: Angiotensin I-converting enzyme and angiotensinogen gene polymorphisms in non-insulin-dependent 
diabetes mellitus. Lack of relationship with diabetic nephropathy and retinopathy in a Caucasian Mediterranean population. Metabolism 1997, 46(8):976-80.

32. Ohno T, Kawazu S, Tomono S: Association analyses of the polymorphisms of angiotensin-converting enzyme and angiotensinogen genes with diabetic nephropathy in Japanese non-insulin-dependent diabetics. Metabolism 1996, 45(2):2। $18-22$.

33. Wong TY, et al.: Lack of association of angiotensin-converting enzyme (DD/II) and angiotensinogen M235T gene polymorphism with renal function among Chinese patients with type II diabetes. Am J Kidney Dis 1999, 33(6): 1064-70.

34. Ringel J, et al:: Genetic variants of the renin-angiotensin system, diabetic nephropathy and hypertension. Diabetologia 1997, 40(2): 193-9.

35. Staessen JA, et al.: M235T angiotensinogen gene polymorphism and cardiovascular renal risk. J Hypertens 1999, I7(I):9-17.

36. Prasad $P$, et al.: Chronic renal insufficiency among Asian Indians with type 2 diabetes: I. Role of RAAS gene polymorphisms. BMC Med Genet 2006, 7:42.

37. Hsu CC, et al.: Genetic variation of the renin-angiotensin system and chronic kidney disease progression in black individuals in the atherosclerosis risk in communities study. J Am Soc Nephrol 2006, 17(2):504-12.

\section{Pre-publication history}

The pre-publication history for this paper can be accessed here:

http://www.biomedcentral.com/1471-2369/10/9/prepub
Publish with Bio Med Central and every scientist can read your work free of charge

"BioMed Central will be the most significant development for disseminating the results of biomedical research in our lifetime. "

Sir Paul Nurse, Cancer Research UK

Your research papers will be:

- available free of charge to the entire biomedical community

- peer reviewed and published immediately upon acceptance

- cited in PubMed and archived on PubMed Central

- yours - you keep the copyright 